\title{
La indagación científica promovida en el aula de ciencias naturales: estudio de caso en educación básica y media
}

\author{
Scientific inquiry promoted in the natural sciences classroom: case \\ study in basic and middle education
}

\section{Yasna Mora-Cortes}

ymora@magisteredu.ucsc.cl

Código ORCID: 0000-0003-2158-6859

\section{Zenahir Siso-Pavón}

zsiso@ucsc.cl

Código ORCID: 0000-0002-0523-6392

Universidad Católica de la Santísima Concepción, Concepción, Chile

Recibido febrero 2021 / Arbitrado marzo 2021 / Aceptado abril 2021 / Publicado mayo 2021

\section{Resumen}

Este estudio se planteó explorar la indagación científica que se promueve en el aula de ciencias cuando los profesores emplean este enfoque didáctico. La investigación fue de tipo cualitativo- interpretativo con diseño de estudio de casos. La muestra estuvo conformada por tres profesores de ciencias cuyas prácticas docentes presentan una aproximación al enfoque indagatorio. El estudio aporta información sobre el discurso de los profesores analizado a partir de entrevistas semiestructuradas, observaciones de clases y el análisis de las planificaciones de aula. Para ello se realizó la codificación, reducción y triangulación de datos. Como hallazgos principales se encontró que los profesores implementan procesos indagatorios en el aula de acuerdo con las concepciones individuales y con el significado que les otorgan a la indagación, considerándola como un modelo de enseñanza de las ciencias que permite identificar una situación problemática, desarrollar conocimiento científico escolar transferible, desarrollar habilidades y actitudes propias del quehacer científico.

\footnotetext{
Abstract

This study set out to explore the scientific inquiry that is promoted in the science classroom when teachers use this didactic approach. The research was qualitative-interpretive with a case study design. The sample consisted of three science teachers whose teaching practices present an approximation to the inquiry approach. The study provides information on the teachers' discourse analyzed from semi-structured interviews, class observations and the analysis of classroom plans. For this, the data coding, reduction and triangulation were carried out. As main findings, it was found that teachers implement inquiry processes in the classroom according to individual conceptions and with the meaning they give to inquiry, considering it as a science teaching model that allows identifying a problematic situation, developing scientific knowledge transferable school, develop skills and attitudes typical of scientific work.
}

Palabras clave:

Indagación científica; habilidades científicas; finalidad pedagógica, conocimiento científico 


\section{INTRODUCCIÓN}

$\mathrm{F}$ rente al desarrollo de un mundo globalizado, es importante entender que toda la población necesita de una cultura científica y tecnológica para aproximarse y comprender la complejidad y globalidad de la realidad contemporánea, para desarrollar habilidades que le permitan desenvolverse en la vida cotidiana y para relacionarse con su entorno, con el mundo del trabajo, de la producción y del estudio (Arteaga, Armada y Del Sol, 2016).

De esta forma, resulta significativo pensar que frente a una sociedad actual que avanza a pasos agigantados en el terreno de la cultura científica, la educación formal continúa enfrentando desafíos en relación a la enseñanza de las ciencias, ya que ni el currículum ni las metodologías empleadas logran alinearse esencialmente con los enfoques pedagógicos que acerquen la ciencia a la vida cotidiana y que responden a las necesidades actuales de una sociedad que demanda alfabetización científica en sus ciudadanos.

Los objetivos de los programas en enseñanza de las ciencias son específicos a cada contexto, y por lo mismo cada país debe definir el propósito de la enseñanza de las ciencias a la que quiere enfocarse y ver cómo se llevará a cabo. Así como también, debe garantizar que la educación científica esté al alcance de todos los niños y jóvenes.

Con esto, la enseñanza de las ciencias se desarrolla en los colegios desde la educación parvularia, con el fin de acercar a los niños a la comprensión de la naturaleza y sus fenómenos. Sin embargo, la enseñanza de las ciencias en Chile ha sufrido cambios curriculares recientemente, es por ello, que a partir del año 2009 el Ministerio de Educación (MINEDUC) ha realizado ajustes curriculares a todos los subsectores de aprendizaje, los cuales incluyen a las asignaturas científicas. Estos ajustes curriculares, en especial en ciencias, tiene como finalidad, que los estudiantes desarrollen habilidades de pensamiento distintivas del quehacer científico y una comprensión del mundo natural y tecnológico, basada en el conocimiento proporcionado por la ciencias naturales. 
Considerando esta nueva propuesta ministerial, tanto los programas de estudios como los textos escolares aparecen actualmente enfocados a brindar ciertas orientaciones pedagógicas y didácticas al docente para desarrollar en sus estudiantes las habilidades del pensamiento científico orientados en indagación. Dada la importancia de este nuevo enfoque, esta investigación tiene como objetivo explorar los procesos de indagación científica que son promovidos en el aula de ciencias cuando los profesores desarrollan las clases bajo este enfoque didáctico. Lo que condujo a la formulación de la pregunta de investigación ¿Cómo son los procesos de indagación científica que promueven los profesores de ciencias naturales cuando desarrollan los contenidos científicos?

Esto genera sin lugar a duda una reflexión respecto a cómo se está desarrollando la educación científica en el sistema escolar chileno, y se originan por consiguiente, una serie de interrogantes: ¿Cómo se está enseñando ciencias a los estudiantes chilenos? ¿Los profesores están desarrollando habilidades de investigación o de pensamiento científico en sus estudiantes? ¿Las situaciones de enseñanza implementadas por los docentes en el aula de ciencias se asocian con la indagación científica? Estas interrogantes toman real importancia si se piensa que, según el currículum formal en ciencias, enfocado a los planes y programas, han sido diseñados para facilitar la adquisición de conocimientos, habilidades y valores a todos los y las estudiantes.

Justamente para desarrollar estas habilidades de investigación y del pensamiento científico se debe aplicar un nuevo enfoque, distinto a la tradicional forma de enseñar ciencias en los colegios. De tal forma, el desarrollo de habilidades científicas sólo será posible en tanto los docentes conozcan y desarrollen diversas estrategias de enseñanza, las cuales de manera efectiva generen aprendizajes significativos en sus estudiantes, considerando las tres áreas del saber: conocimientos, habilidades y actitudes (García, 2011). Es por ello, que se hace necesario indagar e implementar nuevos modelos de enseñanza de tal forma que los alumnos no solo adquieran conocimientos memorísticos, sino que cuenten con las herramientas para enfrentarse a un mundo cambiante. 


\section{MARCO TEÓRICO}

$\mathrm{D}$ entro de estos nuevos modelos de enseñanza, que contribuyen al desarrollo de habilidades científicas se encuentra la indagación científica, la cual se basa exclusivamente en una enseñanza centrada en el alumno, en donde el docente orienta la construcción de conocimientos científicos en el alumnado a través de actividades concretas que involucran el poner en juego una serie de competencias relacionadas con el quehacer científico (González et al., 2012).

En el ámbito de la educación en ciencias el término "indagación" es a menudo entendido como uno de los objetivos de aprendizaje 0 , más comúnmente, como una metodología de enseñanza. La enseñanza de la ciencia basada en la indagación científica se ha comprendido de diversas formas a través de los años y se ha promovido desde una variedad importante de perspectivas. Algunas perspectivas han hecho énfasis en la naturaleza activa del estudiante, mientras otras han relacionado indagación con una aproximación de descubrimiento o con el desarrollo de procesos y habilidades relacionadas con el método de hacer investigación científica.

\section{Indagación científica como pilar del cambio educativo en ciencias}

Desde que John Dewey, uno de los primeros formadores en ciencias en los Estados Unidos de América (EUA) presentara por primera vez el concepto de indagación en 1910, una diversidad de educadores e investigadores lo han utilizado. Según Barrow (2006) no existe una definición clara de lo que es indagación y tampoco se ha alcanzado un acuerdo sobre cómo definirla.

Estas dificultades para definir la indagación vienen desde Dewey (1910) recomendó la inclusión de la indagación en el currículum de ciencias (preescolar a secundaria), además de recomendar que se empezara a formar a los nuevos maestros en indagación. Así pues, se refirió a que los problemas estudiados deben tener una relación directa con la experiencia de los estudiantes y deben estar dentro de su nivel intelectual y académico para, de esta forma, fomentar que los estudiantes se 
conviertan en aprendices activos en busca de sus propias respuestas.

En 1996 el Consejo Nacional de Investigación de Estados Unidos de América (National Research Council, NRC, 1996, p. 23) presenta la siguiente definición: Indagación: "Las diversas formas en las que los científicos estudian el mundo natural y proponen explicaciones basadas en la evidencia derivada de su trabajo. La indagación también se refiere a las actividades de los estudiantes en la que ellos desarrollan conocimiento y comprensión de las ideas científicas". Martin-Hansen (2002) reafirma esta perspectiva al expresar que "la indagación se refiere o al trabajo que realiza el investigador para estudiar el mundo natural o a las actividades de los estudiantes que 'imitan' lo que los científicos hacen."

Hasta ahora quienes han definido la indagación se han enfocado en lo que debe hacer un estudiante, dejando de lado lo que se espera de los docentes. En este sentido, Anderson (2007) hace una especificación relevante que ha de incorporar explícitamente otra mirada: la enseñanza basada en la indagación. En este mismo artículo, Anderson resalta tres formas diferentes en que la NRC utiliza la palabra indagación en sus documentos: la conocida como "indagación científica" (scientific inquiry, las diversas formas en que los científicos estudian el mundo), la enseñanza a través de la indagación y el aprendizaje basado en la indagación.

Así de acuerdo con Anderson (2007), señala que existen, al menos, tres visiones de lo que es la indagación: i) lo que hacen los científicos; ii) lo que hacen y aprenden los estudiantes, y iii) lo que saben y saben hacer los profesores en el aula.

El concepto "Indagación científica" puede ser entendido como objetivos de aprendizaje, una metodología de enseñanza o un enfoque pedagógico, es decir, un conjunto de conocimientos y creencias que guían la enseñanza de las ciencias (Abell, Smith y Volkmann, 2006)) El uso de la indagación como enfoque pedagógico no sólo debiera llevar a una mayor comprensión de conceptos científicos y al desarrollo de habilidades científicas, sino también a una mayor comprensión acerca de la Naturaleza de la Ciencia, es decir, a la comprensión del desarrollo del conocimiento científico y su relación con la sociedad. 
Algunos de los principales referentes en Naturaleza de la Ciencia afirman que "el conocimiento actual sugiere que la mejor forma de aprender ciencias es a través de la indagación. Se cree que los estudiantes aprender mejor los conceptos científicos haciendo ciencia" (Lederman, Lederman y Antink, 2013, pp. 142143). Bevins y Price (2016) consideran que la indagación es el mejor método para enseñar ciencias, promover habilidades de investigación en los estudiantes y ayudarles a interiorizar nuevo conocimiento en la búsqueda de respuesta a preguntas científicas, previamente formuladas. Así, afirman que "esta aproximación aporta al alumnado un mayor control del propio aprendizaje y le permite navegar activamente por los caminos que aumentan su comprensión y motivación y mejoran su actitud hacia la práctica científica, incrementando su auto-estima y su capacidad para manejar nuevos datos en un mundo cada vez más complejo" (p. 19).

En el informe de expertos Science Education for Responsible Citizenship (European Union, 2015) se define la indagación como un proceso complejo de construcción de significados y modelos conceptuales coherentes, en el que los estudiantes formulan cuestiones, investigan para encontrar respuestas, comprenden y construyen nuevo conocimiento y comunican su aprendizaje a otros, aplicando el conocimiento de forma productiva a situaciones no familiares (European Union, 2015, p. 68). En los últimos años se han propuesto nuevas conceptualizaciones de esta metodología. Pedaste et al. (2015) proponen un modelo no lineal que incluye cinco fases y 9 sub-fases interrelacionadas entre sí a través de múltiples caminos, que representan la diversidad de posibles implementaciones en el aula. La discusión, comunicación y reflexión se proponen como elementos transversales del modelo que determinan en gran medida la calidad de la indagación llevada a cabo por el alumnado. Los autores justifican esta idea aludiendo a la influencia que estas actividades tienen sobre la metacognición y auto-regulación del aprendizaje. 


\section{MÉTODO}

L a investigación se sustenta en la metodología cualitativa ya que el fenómeno en estudio se ajusta a una mirada comprensiva e interpretativa, a través de la cual se analizaron las concepciones de los docentes, sus acciones de enseñanza, las habilidades de investigación y de pensamiento científico que promueven y la finalidad de implementar la indagación científica en el aula, directamente por los propios actores del fenómeno estudiado. En esta investigación se utilizó el estudio de caso, ya que el propósito era acceder a la comprensión de un fenómeno en particular tal como lo ven los docentes participantes. Se desarrolló un estudio de caso de tipo instrumental, trabajando con tres docentes: dos profesores de ciencias naturales y biología de un colegio subvencionado y un profesor de enseñanza básica que imparte la asignatura de Ciencias Naturales en un establecimiento municipal. La selección de los docentes participantes, se realizó de acuerdo a razones teóricas (Simons, 2011) relacionadas con los fines de la investigación. Se empleó un código para cada profesor resguardo de anonimato. Los profesores en estudio se reconocieron como:

Caso 1: PROFESOR VA. Profesor de Educación General Básica que imparte la asignatura de Ciencias Naturales en un Establecimiento Municipal, participante de un programa de perfeccionamiento relacionado con indagación científica impulsado por el MINEDUC (Ministerio de Educación).

Caso 2: PROFESOR AL. Profesor de Biología, quien se desarrolla profesionalmente en un Establecimiento Subvencionado. Ha sido partícipe de un programa de perfeccionamiento docente relacionado con la indagación en el aula impulsado por el MINEDUC.

Caso 3: PROFESOR KA. Profesor de Ciencias Naturales y Biología, quien imparte la asignatura de Ciencias Naturales en enseñanza básica y Biología en enseñanza media, en un Establecimiento Subvencionado.

Las técnicas que se aplicaron en este estudio fueron: entrevista semiestructurada, observación participante y análisis documental. Para el análisis de los resultados se utilizó como fuentes de información las entrevistas semiestructuradas a los tres profesores, las filmaciones de clases y el análisis documental de las 
planificaciones de aula de los docentes informantes. Se transcribieron las entrevistas y filmaciones para posteriormente realizar una codificación guiada por conceptos (Gibbs, 2012) donde el levantamiento de códigos surgió de manera múltiple en función de lo que fue apareciendo como relevante en los datos, en cuyo caso, se utilizaron conceptos y códigos surgidos del vocabulario de los informantes y de base teórica del investigador. Estos conceptos y códigos permitieron establecer una relación entre ellos para dar origen a las categorías y subcategorías. En la Tabla 1 se pueden apreciar las categorías de análisis utilizadas con las correspondientes subcategorías.

Tabla 1. Categorías y subcategorías establecidas.

\begin{tabular}{ll}
\hline Categorías & Subcategorías \\
\hline Concepto de indagación & $\begin{array}{l}\text { Métodos de enseñanza } \\
\text { Enfoque didáctico }\end{array}$ \\
Tipos de Indagación & $\begin{array}{l}\text { Indagación Guiada } \\
\text { Indagación Acoplada }\end{array}$ \\
Finalidad Pedagógica & $\begin{array}{l}\text { Adquirir Conocimiento científico } \\
\text { Desarrollo de Habilidades }\end{array}$ \\
& Desarrollo de Actitudes científicas \\
Habilidades Científicas & Concepto de Habilidad científica \\
& Tipos de Habilidades Científicas
\end{tabular}

Una vez establecidas las categorías y subcategorías se analizaron de acuerdo a los datos obtenidos de cada informante, para posteriormente realizar una triangulación de los datos.

\section{RESULTADOS}

El proceso de análisis e interpretación involucró una primera fase de revisión minuciosa de la información obtenida a través de cada una de las técnicas recolección de información para cada caso, y su correspondiente codificación y categorización. A continuación, 
se muestra parte del proceso realizado como una cuenta detallada de lo encontrado para una de las categorías del estudio:

Para la Categoría Finalidad Pedagógica de la Indagación, el discurso docente está dirigido a interpretar el propósito de implementar en las prácticas docentes la indagación científica en el aula, asumiendo una intención pedagógica en los procesos indagatorios que se aplican en el aula con los estudiantes.

"Mira, la indagación no solamente desarrolla habilidades; desarrolla actitudes y principalmente conocimiento significativo; es decir, nuevos conocimientos. Pero, estos conocimientos científicos que los apliquen; no que queden ahí guardados. Si tú no aplicas lo que aprendes, ¿de qué sirve? Un niño memorión... ¿de qué te sirve si no sabe aplicar?" [ENTVA_37]

Cuando se le pregunta al profesor VA para qué realiza indagación en sus clases, él responde que la indagación, no solamente desarrolla habilidades; desarrolla actitudes y conocimiento significativo, es decir, nuevos conocimientos, los cuales deben aplicarse a diversas situaciones específicas. Se deduce entonces, que la aplicación de los conocimientos adquiridos a la práctica se puede llevar a cabo si se ponen en marcha procesos de transferencia. En este contexto, significaría aplicar habilidades, actitudes y principalmente los conocimientos científicos adquiridos en el aula de ciencias a los problemas y situaciones de la vida cotidiana.

En relación con las clases observadas, se realizaron 15 filmaciones de clases realizadas a los profesores participantes de este estudio investigativo, tales evidencias se efectuaron en el aula de clases, en salidas pedagógicas y en el laboratorio de ciencias de los respectivos establecimientos educacionales. Es importante señalar, que de todas las clases observadas, sólo en 7 de ellas se evidenciaron procesos indagatorios concretos, y en las clases restantes se evidenciaba una aproximación hacia la enseñanza tradicional. A continuación se presenta un extracto de una filmación realizada por el profesor KA en el laboratorio de ciencias, con alumnos de primer año de educación media, dentro del análisis de la categoría Finalidad pedagógica de la indagación científica: 
Profesor: Miren jóvenes pongan atención acá, observen lo que está pasando, su compañera trajo hojas de ciruelo rojo y realizó el procedimiento. Qué hipótesis se plantearon al comienzo ustedes, había o no clorofila en estas hojas.

Alumno: Por el color pensamos que nos iba a salir un pigmento rojo.

Profesor: ¿Y qué pasó?, ¿De qué color salió ese pigmento?

Alumno: Verde!!!

Profesor: ¿Y qué sucedió entonces?

Alumno: estábamos equivocados....

Profesor: No, no es que ustedes estuvieran equivocados, sino que estaban haciendo ciencia.....Se plantearon preguntas, formularon una hipótesis y la pusieron a prueba en un procedimiento experimental, y gracias a esto pudieron corroborar o descartar su hipótesis, Ahora tienen resultados basados en evidencias, ieso es importante! Los mayores logros en ciencia han sido alcanzados por acierto y error. Pero los errores a veces son importantes para dirigir por otro rumbo la investigación, ya vamos, ivamos a trabajar! [CLAS1KA_11]

El docente manifiesta una intención clara de desarrollar a través de un procedimiento experimental, actitudes científicas en los alumnos, las cuales se relacionan con la tolerancia y perseverancia en el trabajo en ciencias, haciendo hincapié en que los errores no son del todo negativos, ya que pueden encausar la investigación hacia otra dirección. El profesor asume que dentro del trabajo experimental los alumnos hacen ciencia, se plantean preguntas, formulan hipótesis y las ponen a prueba en un procedimiento experimental, obteniendo resultados basados en evidencias. Por lo consiguiente, este conjunto de elementos sería parte de los procesos indagatorios que el profesor implementa en el aula.

De acuerdo con el análisis del contenido documental, fueron analizadas las planificaciones de aula de los 3 profesores participantes, las cuales fueron empleadas para organizar las unidades didácticas de acuerdo al currículum imperante en ciencias. En relación a lo anterior, cada establecimiento educacional impone sus propias normativas y disposiciones de acuerdo al formato y exigencias estipuladas en este documento oficial. Dentro de las planificaciones analizadas, para el caso del profesor VA se 
encontraron actividades de enseñanzas que apuntan evidentemente hacia el enfoque indagatorio. Un ejemplo de esta planificación de aula se enmarca dentro de la unidad didáctica de "Los Microorganismos y Barreras defensivas del cuerpo humano" correspondiente a sexto año de Enseñanza Básica. Para la categoría "Tipos de indagación", la descripción de las actividades de enseñanza señala lo siguiente:

Para motivar a los estudiantes, y focalizar su atención, el profesor les plantea una situación problemática:

"Juan es un niño de 12 años, muy sano, pero un día va al cumpleaños de su gran amiga Constanza y hay unos completos muy ricos con mayonesa casera, por lo que se sirvió dos completos. Al otro día, comienza a sentirse mal; tiene náuseas, dolor abdominal, diarrea y fiebre. Su mamá le toma la temperatura, sorprendiéndose y preocupándose por tener $39^{\circ}$, por lo que decide llevarlo a médico. El médico lo examina y lo envía a unos exámenes, los cuales salen alterados y le comenta que lamentablemente tiene Salmonelosis, causándole una intoxicación por salmonella."

¿Podrías ayudarlo y explicarle lo que le sucedió? ¿Podrías elaborar una predicción? ¿Cuál es la variable en estudio? ¿Cómo se contagió esta enfermedad? ¿Qué microorganismo es el responsable? ¿Qué medidas de prevención le recomendarías? ¿Cómo podrías aplicar estos conocimientos a tu vida cotidiana? ¿Qué otra enfermedad conoces contagiada por microorganismos? [PLANVA_3]

Para la primera etapa de la indagación el docente focaliza la atención del estudiante y los motiva planteándole una situación problemática inicial. Es preciso señalar que en este momento de la clase, el docente cumple el rol de guía, proporcionando a los alumnos una situación problemática, generando a partir de ella la investigación en de los alumnos. Además, es el docente quién dirige y entrega las instrucciones para desarrollar y ejecutar las secuencias didácticas que generarán habilidades científicas. El docente propone la elaboración de una predicción, habla de variable de estudio y la aplicación de conocimiento a la vida cotidiana. Claramente está en una dimensión que abarca y promueve el desarrollo de habilidades de investigación y de pensamiento científico. 
Después de realizado el análisis de la información producida con el modelo de trabajo anterior, se trabajó en la triangulación de estos análisis, ordenada por tablas de categorías para cada profesor participante y por categorías de estudio con la finalidad de, a través de cada caso, tener una mirada global del fenómeno en estudio. Las tablas 2, 3, 4 y 5 entregan información en cada una de las categorías de análisis de acuerdo a la entrevista realizada, la observación de clase y la planificación de aula, para cada uno de los profesores en estudio.

De acuerdo con la categoría "Concepto de indagación" (ver Tabla 2), es factible establecer que los docentes presentan una concepción distinta de lo que ellos consideran indagación científica, para dos de ellos, el profesor VA y KA, la indagación es concebida como una metodología de enseñanza, considerándola como "metodología indagatoria", dirigida a un objetivo específico que sería el logro de aprendizajes a través de actividades y quehaceres científicos que involucren investigación. El docente AL ubica a la indagación como un enfoque didáctico, un modelo de enseñanza de las ciencias, que puede ser aplicado en las aulas para lograr ciertos saberes propios del quehacer científico, lo considera como una forma de hacer ciencia escolar símil a la ciencia que realizan los eruditos, concretándose en la práctica como un proceso real de ejecutar una investigación científica en el aula. 
Tabla 2. Categoría. Concepto de indagación.

\begin{tabular}{|c|c|c|c|}
\hline Profesor & Entrevista & Observación & $\begin{array}{c}\text { Planificación } \\
\text { de aula }\end{array}$ \\
\hline VA & $\begin{array}{l}\text { Desde su discurso el } \\
\text { profesor se refiere a } \\
\text { la indagación } \\
\text { científica como un } \\
\text { método para la } \\
\text { enseñanza de las } \\
\text { ciencias. Según su } \\
\text { percepción se refiere } \\
\text { a una "metodología } \\
\text { didáctica" que logra } \\
\text { sacar al alumno de lo } \\
\text { rutinario, } \\
\text { abandonando la } \\
\text { enseñanza } \\
\text { tradicional y que } \\
\text { permite a los } \\
\text { estudiantes obtener } \\
\text { aprendizajes de } \\
\text { manera entretenida y } \\
\text { significativa. Además } \\
\text { esta nueva } \\
\text { metodología favorece } \\
\text { la aplicación de } \\
\text { conocimientos en } \\
\text { diversas situaciones } \\
\text { problemáticas. }\end{array}$ & $\begin{array}{l}\text { Desde su actuar el } \\
\text { docente evidencia } \\
\text { concebir la } \\
\text { indagación como un } \\
\text { método de } \\
\text { enseñanza, } \\
\text { refiriéndose y } \\
\text { presentándola a sus } \\
\text { alumnos en sus } \\
\text { clases como la } \\
\text { metodología } \\
\text { indagatoria. A través } \\
\text { de las actividades de } \\
\text { enseñanza realizadas } \\
\text { promueve los pasos } \\
\text { en las diversas } \\
\text { etapas de la } \\
\text { indagación, } \\
\text { realizando diversos } \\
\text { procedimientos en } \\
\text { forma secuencial. }\end{array}$ & $\begin{array}{l}\text { Desde lo que registra } \\
\text { en sus } \\
\text { planificaciones como } \\
\text { documento oficial } \\
\text { que rige su actuar } \\
\text { docente, se menciona } \\
\text { la invitación a } \\
\text { trabajar en una } \\
\text { actividad } \\
\text { indagatoria, } \\
\text { registrándose } \\
\text { además las etapas de } \\
\text { la indagación: } \\
\text { Focalización, } \\
\text { experimentación, } \\
\text { reflexión y } \\
\text { aplicación. Además } \\
\text { en las actividades } \\
\text { descritas se } \\
\text { promueve la } \\
\text { realización de } \\
\text { procedimientos } \\
\text { secuenciales para } \\
\text { trabajar con } \\
\text { indagación en el } \\
\text { aula. }\end{array}$ \\
\hline $\mathbf{A L}$ & $\begin{array}{l}\text { Desde su discurso el } \\
\text { profesor se refiere a } \\
\text { la indagación } \\
\text { científica como un } \\
\text { modelo de } \\
\text { aprendizaje de las } \\
\text { ciencias, si bien se } \\
\text { habla de modelo de } \\
\text { aprendizaje, se está } \\
\text { aludiendo a un } \\
\text { enfoque didáctico } \\
\text { para orientar la } \\
\text { enseñanza de las } \\
\text { ciencias en el aula. } \\
\text { Alude a una manera } \\
\text { de hacer ciencia } \\
\text { escolar similar a la } \\
\text { ciencia erudita. Esta } \\
\text { mirada incluye la } \\
\text { noción del modelo de } \\
\text { enseñanza por } \\
\text { investigación dentro } \\
\text { de la didáctica de las } \\
\text { ciencias. }\end{array}$ & $\begin{array}{l}\text { Durante su actuar en } \\
\text { las diversas clases } \\
\text { observadas el } \\
\text { docente no se refiere } \\
\text { a un enfoque } \\
\text { didáctico para } \\
\text { señalar la indagación } \\
\text { científica, sin } \\
\text { embargo, se advierte } \\
\text { que la indagación } \\
\text { puede ser } \\
\text { considerada como un } \\
\text { proceso investigativo } \\
\text { a partir de un } \\
\text { contenido disciplinar, } \\
\text { generando un } \\
\text { modelo de } \\
\text { investigación } \\
\text { científica. }\end{array}$ & $\begin{array}{l}\text { Resulta difícil } \\
\text { confirmar a la } \\
\text { indagación como } \\
\text { enfoque didáctico } \\
\text { observando los } \\
\text { registros de la } \\
\text { planificación de aula, } \\
\text { pero si es posible } \\
\text { observar una serie } \\
\text { de actividades } \\
\text { sugeridas, cuya } \\
\text { finalidad y objetivo } \\
\text { se asocia a } \\
\text { desarrollar en los } \\
\text { estudiantes, } \\
\text { conocimiento, } \\
\text { habilidades y } \\
\text { actitudes propias del } \\
\text { trabajo científico. }\end{array}$ \\
\hline
\end{tabular}




\begin{tabular}{|c|c|c|c|}
\hline Profesor & Entrevista & Observación & $\begin{array}{c}\text { Planificación } \\
\text { de aula }\end{array}$ \\
\hline KA & $\begin{array}{l}\text { Desde su discurso el } \\
\text { profesor se refiere a } \\
\text { la indagación como } \\
\text { una metodología que } \\
\text { utiliza diferentes } \\
\text { estrategias de } \\
\text { enseñanza } \\
\text { relacionadas con la } \\
\text { actividad científica } \\
\text { escolar, su finalidad } \\
\text { es enseñar } \\
\text { conocimiento } \\
\text { científico, } \\
\text { competencias y } \\
\text { habilidades en los } \\
\text { alumnos. Como un } \\
\text { proceso reflexivo } \\
\text { para tomar } \\
\text { conciencia de su } \\
\text { propio aprendizaje. }\end{array}$ & $\begin{array}{l}\text { De acuerdo a la } \\
\text { concepción de } \\
\text { indagación que tiene } \\
\text { el profesor, la utiliza } \\
\text { para desarrollar un } \\
\text { trabajo experimental } \\
\text { basado en } \\
\text { investigación como } \\
\text { un método de } \\
\text { enseñanza, con pasos } \\
\text { o procedimientos } \\
\text { sistemáticos para } \\
\text { alcanzar } \\
\text { aprendizajes y que } \\
\text { conducirán la } \\
\text { investigación. }\end{array}$ & $\begin{array}{l}\text { Desde lo que registra } \\
\text { en sus } \\
\text { planificaciones, en } \\
\text { las actividades aquí } \\
\text { descritas se } \\
\text { promueven la } \\
\text { realización de } \\
\text { procedimientos } \\
\text { secuenciales para } \\
\text { trabajar con } \\
\text { indagación en el } \\
\text { aula. }\end{array}$ \\
\hline
\end{tabular}

En la categoría "Tipos de indagación" (ver Tabla 3), se deja de manifiesto que los tres profesores realizan principalmente una indagación de tipo guiada en sus clases, donde es el profesor quien en su rol de guía, dirige y orienta al alumno para lograr la apropiación tanto de un cuerpo de conocimientos científicos básicos, como de habilidades científicas. Esto se ve reflejado tanto en sus discursos como en el actuar docente. Se sostiene que es el docente quien debe comenzar la indagación a través de una interrogante, una pregunta investigable, sin embargo, se le deja al estudiante, en ciertas ocasiones, tomar decisiones para alcanzar la solución o respuesta. Requiere que el estudiante cumpla un rol protagónico en la adquisición de habilidades científicas, para que él pueda reflexionar desde su propia experiencia y conducir la investigación científica. Esto se relaciona, en parte, con la indagación acoplada para establecer una labor en conjunto. 
Tabla 3. Categoría. Tipos de indagación.

\begin{tabular}{|c|c|c|c|}
\hline Profesor & Entrevista & Observación & $\begin{array}{c}\text { Planificación } \\
\text { de aula }\end{array}$ \\
\hline VA & $\begin{array}{l}\text { Desde su discurso se } \\
\text { considera que el } \\
\text { profesor debe } \\
\text { entregar } \\
\text { inicialmente una } \\
\text { pregunta que } \\
\text { involucre una } \\
\text { problemática } \\
\text { investigable para } \\
\text { fomentar una } \\
\text { motivación adecuada } \\
\text { en los alumnos. Bajo } \\
\text { la orientación y } \\
\text { supervisión } \\
\text { constante del } \\
\text { profesor, los } \\
\text { alumnos desarrollan } \\
\text { los procedimientos y } \\
\text { habilidades propias } \\
\text { del quehacer } \\
\text { científico, los } \\
\text { estudiantes discuten } \\
\text { los resultados y } \\
\text { elaboran preguntas } \\
\text { para las cuales } \\
\text { hacen una } \\
\text { predicción de lo que } \\
\text { sucederá, planean } \\
\text { cómo colectarán los } \\
\text { datos y llevan a cabo } \\
\text { la investigación. }\end{array}$ & $\begin{array}{l}\text { En su actuar el } \\
\text { profesor entrega } \\
\text { ciertas orientaciones } \\
\text { a sus alumnos, } \\
\text { dirigiendo la } \\
\text { investigación en el } \\
\text { aula. Lo que } \\
\text { evidencia } \\
\text { claramente el tipo } \\
\text { de indagación que } \\
\text { promueve en sus } \\
\text { clases. Se trata } \\
\text { entonces de una } \\
\text { indagación guiada, } \\
\text { donde el docente } \\
\text { entrega una } \\
\text { problemática inicial } \\
\text { y guía el actuar de } \\
\text { los estudiantes. Sin } \\
\text { embargo, en algunas } \\
\text { clases son los } \\
\text { alumnos quienes } \\
\text { formulan esa } \\
\text { problemática para } \\
\text { generar a partir de } \\
\text { ahí la investigación. }\end{array}$ & $\begin{array}{l}\text { En registro de las } \\
\text { planificaciones de } \\
\text { aula el docente deja } \\
\text { de manifiesto su rol } \\
\text { en el planteamiento } \\
\text { de una situación } \\
\text { problemática. } \\
\text { Además es él quien } \\
\text { propone preguntas } \\
\text { guiadas para } \\
\text { generar } \\
\text { conocimiento } \\
\text { científico y } \\
\text { habilidades } \\
\text { científicas, } \\
\text { preguntas que } \\
\text { finalmente } \\
\text { promoverán el } \\
\text { aprendizaje de los } \\
\text { estudiantes. }\end{array}$ \\
\hline $\mathbf{A L}$ & $\begin{array}{l}\text { Desde su discurso se } \\
\text { relaciona a la } \\
\text { indagación con la } \\
\text { idea de articular un } \\
\text { proyecto } \\
\text { investigativo en el } \\
\text { aula, que bajo la } \\
\text { dirección del } \\
\text { profesor los } \\
\text { estudiantes } \\
\text { consiguen } \\
\text { resultados. } \\
\text { El profesor es quien } \\
\text { dirige y orienta el } \\
\text { camino que debe } \\
\text { seguir el alumno, sin } \\
\text { embargo, se le deja } \\
\text { al estudiante, en } \\
\text { ciertas ocasiones, } \\
\text { tomar decisiones. }\end{array}$ & $\begin{array}{l}\text { En su desempeño en } \\
\text { el aula el docente } \\
\text { inicia la clase } \\
\text { proponiendo una } \\
\text { investigación } \\
\text { científica a partir de } \\
\text { una pregunta o } \\
\text { trabajo } \\
\text { experimental. Se } \\
\text { evidencia que en } \\
\text { ciertos momentos de } \\
\text { la clase los alumnos } \\
\text { son capaces de } \\
\text { tomar decisiones } \\
\text { respecto al trabajo } \\
\text { que implica la } \\
\text { búsqueda de la } \\
\text { verdad, encontrar } \\
\text { soluciones y dirigir } \\
\text { en cierta forma la } \\
\text { investigación. }\end{array}$ & $\begin{array}{l}\text { En registro de las } \\
\text { planificaciones de } \\
\text { aula es posible } \\
\text { evidenciar que el } \\
\text { profesor lleva a cabo } \\
\text { diversas estrategias } \\
\text { didácticas o } \\
\text { actividades de } \\
\text { enseñanza para } \\
\text { implementar } \\
\text { indagación en el } \\
\text { aula, guiando } \\
\text { específicamente el } \\
\text { proceso de } \\
\text { investigación } \\
\text { experimental en } \\
\text { laboratorio. }\end{array}$ \\
\hline
\end{tabular}




\begin{tabular}{|c|c|c|c|}
\hline Profesor & Entrevista & Observación & $\begin{array}{c}\text { Planificación } \\
\text { de aula }\end{array}$ \\
\hline $\mathbf{A L}$ & $\begin{array}{l}\text { Requiere que el } \\
\text { estudiante cumpla } \\
\text { un rol protagónico } \\
\text { en la adquisición de } \\
\text { habilidades } \\
\text { científicas, para que } \\
\text { él pueda reflexionar } \\
\text { desde su propia } \\
\text { experiencia. Esto se } \\
\text { relaciona, en parte, } \\
\text { con la indagación } \\
\text { acoplada para } \\
\text { establecer una labor } \\
\text { en conjunto. }\end{array}$ & & $\begin{array}{l}\text { En las actividades } \\
\text { como los trabajos } \\
\text { grupales o análisis } \\
\text { de textos se puede } \\
\text { deducir que los } \\
\text { alumnos realizarían } \\
\text { un trabajo más } \\
\text { autónomo, tomando } \\
\text { decisiones sobre las } \\
\text { acciones a seguir. }\end{array}$ \\
\hline KA & $\begin{array}{l}\text { Desde su discurso se } \\
\text { sostiene que lo ideal } \\
\text { es que la } \\
\text { problemática } \\
\text { indagatoria nazca } \\
\text { del alumno, sin } \\
\text { embargo, el profesor } \\
\text { puede orientar el } \\
\text { camino para } \\
\text { construir } \\
\text { aprendizaje. El } \\
\text { docente cumple un } \\
\text { rol de guía en el } \\
\text { proceso de } \\
\text { adquisición del } \\
\text { conocimiento } \\
\text { científico, esto se } \\
\text { justifica en el } \\
\text { sentido que los } \\
\text { alumnos no son } \\
\text { íntegramente } \\
\text { autónomos en su } \\
\text { quehacer, por lo que } \\
\text { es el profesor quien } \\
\text { debe acompañar al } \\
\text { alumno para } \\
\text { adquirir ciertas } \\
\text { habilidades que lo } \\
\text { conducirán a lograr } \\
\text { los objetivos de } \\
\text { aprendizaje. }\end{array}$ & $\begin{array}{l}\text { Durante su actuar se } \\
\text { evidencia el rol de } \\
\text { guía del profesor, si } \\
\text { bien no entrega } \\
\text { directamente una } \\
\text { problemática inicial, } \\
\text { si da a entender que } \\
\text { los alumnos deben } \\
\text { plantearse una } \\
\text { pregunta que inicie } \\
\text { la investigación. } \\
\text { Entrega } \\
\text { instrucciones y } \\
\text { orientaciones de } \\
\text { como el alumno } \\
\text { debe seguir su } \\
\text { proceso de } \\
\text { aprendizaje para } \\
\text { desarrollar la } \\
\text { indagación. } \\
\text { Claramente se } \\
\text { puede identificar } \\
\text { como una } \\
\text { indagación de tipo } \\
\text { guiada. }\end{array}$ & $\begin{array}{l}\text { En registro de las } \\
\text { planificaciones de } \\
\text { aula el docente deja } \\
\text { de manifiesto su rol } \\
\text { en el planteamiento } \\
\text { de una situación } \\
\text { problemática por } \\
\text { parte del profesor. } \\
\text { Además es él quien } \\
\text { propone preguntas } \\
\text { guiadas para } \\
\text { generar } \\
\text { conocimiento } \\
\text { científico y } \\
\text { habilidades } \\
\text { científicas, } \\
\text { preguntas que } \\
\text { finalmente } \\
\text { promoverán el } \\
\text { aprendizaje de los } \\
\text { estudiantes. }\end{array}$ \\
\hline
\end{tabular}

De acuerdo con la categoría "Finalidad pedagógica de la indagación" (ver Tabla 4), es posible establecer que los docentes en estudio presentan una claridad en cuanto a la finalidad pedagógica de aplicar indagación científica en el aula: para promover habilidades de investigación, actitudes y conocimiento científico en los estudiantes. Se pone de manifiesto la importancia 
que tiene para los profesores generar conocimiento científico escolar y que el alumno logre la aplicación de estos conocimientos y saberes adquiridos a situaciones de la vida cotidiana. Considerando a la indagación científica como una actividad intencional encaminada a la construcción de un nuevo saber y relacionada con el proceso de ir descubriendo vacíos conceptuales para llegar finalmente a consolidar el nuevo saber teórico. Además, los profesores establecen que la indagación científica es adecuada para el desarrollo de habilidades de investigación científica en el aula escolar, y específicamente se puede apreciar en procedimientos experimentales con la manipulación de material e instrumentos de laboratorio, donde los alumnos trabajan con sus conocimientos previos, formulan hipótesis, realizan predicciones, inferencias y discuten sus resultados obtenidos.

Finalmente los tres profesores concuerdan desde su discurso, su actuar y lo que expresan en sus planificaciones que la indagación científica favorece el desarrollo de actitudes en los alumnos, permitiendo una finalidad formativa y ética en el alumno, el desarrollo de ciertas actitudes propias del quehacer científico como generar curiosidad por el entorno y los fenómenos observados, un clima de respeto y orden, de trabajo colaborativo en grupos y fomentar la tolerancia, la transparencia y la responsabilidad.

Tabla 4. Categoría. Finalidad pedagógica de la indagación.

\begin{tabular}{|c|c|c|c|}
\hline Profesor & Entrevista & Observación & $\begin{array}{c}\text { Planificación } \\
\text { de aula }\end{array}$ \\
\hline VA & $\begin{array}{l}\text { Durante el discurso se } \\
\text { pone de manifiesto la } \\
\text { importancia que tiene } \\
\text { para el profesor generar } \\
\text { conocimiento } \\
\text { significativo en el aula y } \\
\text { que el alumno logre la } \\
\text { aplicación de estos } \\
\text { conocimientos y saberes } \\
\text { adquiridos a situaciones } \\
\text { de la vida cotidiana para } \\
\text { que puedan ser } \\
\text { contextualizados. }\end{array}$ & $\begin{array}{l}\text { Durante su actuar en } \\
\text { el aula, el docente } \\
\text { lleva a cabo diversas } \\
\text { actividades de } \\
\text { enseñanza que } \\
\text { apuntan } \\
\text { directamente a que } \\
\text { el alumno logre } \\
\text { adquirir un } \\
\text { conocimiento } \\
\text { científico. Tal } \\
\text { conocimiento debe } \\
\text { idealmente de ser } \\
\text { incorporados a partir } \\
\text { del entorno directo } \\
\text { del estudiante. }\end{array}$ & $\begin{array}{l}\text { Las actividades de } \\
\text { enseñanza registradas } \\
\text { en las planificaciones } \\
\text { de aula, apuntan al } \\
\text { desarrollo de } \\
\text { conocimiento } \\
\text { científico, se sostiene } \\
\text { además la } \\
\text { socialización de los } \\
\text { conocimientos } \\
\text { obtenidos y una } \\
\text { reflexión del proceso } \\
\text { de aprendizaje, } \\
\text { alcanzando una } \\
\text { metacognición y } \\
\text { regulación de los } \\
\text { aprendizajes } \\
\text { adquiridos. }\end{array}$ \\
\hline
\end{tabular}




\begin{tabular}{|c|c|c|c|}
\hline Profesor & Entrevista & Observación & $\begin{array}{c}\text { Planificación } \\
\text { de aula }\end{array}$ \\
\hline VA & $\begin{array}{l}\text { Además se hace } \\
\text { mención del desarrollo } \\
\text { de habilidades de } \\
\text { investigación científica a } \\
\text { través de actividades de } \\
\text { indagación, } \\
\text { considerando las } \\
\text { capacidades } \\
\text { individuales de cada } \\
\text { estudiante, para que } \\
\text { investiguen y descubran } \\
\text { por sí mismos } \\
\text { fenómenos naturales de } \\
\text { acuerdo a su entorno. } \\
\text { Por último, se hace } \\
\text { referencia que la } \\
\text { indagación científica } \\
\text { favorece el desarrollo de } \\
\text { actitudes en los } \\
\text { alumnos, relacionadas } \\
\text { tanto con el trabajo } \\
\text { científico como con su } \\
\text { vida personal, pone } \\
\text { énfasis por ejemplo en } \\
\text { el respeto hacia los } \\
\text { demás, el desarrollar un } \\
\text { trabajo colaborativo en } \\
\text { los estudiantes, donde el } \\
\text { alumno adquiere un rol } \\
\text { de acuerdo a sus } \\
\text { capacidades o destrezas, } \\
\text { potenciando su } \\
\text { autoestima. }\end{array}$ & $\begin{array}{l}\text { Se evidencia, } \\
\text { además, el desarrollo } \\
\text { de habilidades } \\
\text { científicas, poniendo } \\
\text { bastante énfasis en } \\
\text { el planteamiento de } \\
\text { preguntas } \\
\text { investigables, el } \\
\text { desarrollo de } \\
\text { habilidad de } \\
\text { formulación de } \\
\text { hipótesis e } \\
\text { identificación de } \\
\text { variables en las } \\
\text { clases. Y se } \\
\text { demuestra también } \\
\text { el desarrollo de } \\
\text { ciertas actitudes } \\
\text { propias del quehacer } \\
\text { científico como } \\
\text { generar curiosidad } \\
\text { por el entorno, } \\
\text { predisposición de } \\
\text { búsqueda de verdad, } \\
\text { resolver conflictos y } \\
\text { trabajo colaborativo. }\end{array}$ & $\begin{array}{l}\text { Se insiste del mismo } \\
\text { modo, la aplicación del } \\
\text { de los conocimientos } \\
\text { nuevos a situaciones } \\
\text { de la vida cotidiana. } \\
\text { Se menciona varias } \\
\text { habilidades científicas } \\
\text { dentro del proceso } \\
\text { investigativo que } \\
\text { llevan a cabo los } \\
\text { estudiantes, se } \\
\text { entrega instrucciones } \\
\text { para la búsqueda de } \\
\text { información } \\
\text { bibliográfica, } \\
\text { procedimientos } \\
\text { experimentales, } \\
\text { organización y análisis } \\
\text { de la información, } \\
\text { discusión de } \\
\text { resultados }\end{array}$ \\
\hline $\mathbf{A L}$ & $\begin{array}{l}\text { Durante el discurso se } \\
\text { pone de manifiesto la } \\
\text { importancia que tiene } \\
\text { para el profesor generar } \\
\text { conocimiento científico } \\
\text { escolar. La indagación } \\
\text { científica es adecuada } \\
\text { como enfoque de } \\
\text { enseñanza para las } \\
\text { ciencias, apuntando } \\
\text { específicamente al } \\
\text { desarrollo de } \\
\text { habilidades de } \\
\text { investigación científica } \\
\text { en el aula escolar que se } \\
\text { consideran como ciertas } \\
\text { competencias y } \\
\text { destrezas científicas que } \\
\text { el alumno debería ir }\end{array}$ & $\begin{array}{l}\text { Durante su actuar en } \\
\text { el aula, se observa } \\
\text { una clara intención } \\
\text { del profesor en la } \\
\text { búsqueda de generar } \\
\text { un conocimiento } \\
\text { científico, } \\
\text { considerando a la } \\
\text { investigación } \\
\text { científica como una } \\
\text { actividad intencional } \\
\text { encaminada a la } \\
\text { construcción de un } \\
\text { nuevo saber teórico. } \\
\text { Se evidencia el } \\
\text { desarrollo de } \\
\text { habilidades } \\
\text { científicas, se trabaja } \\
\text { en la búsqueda de }\end{array}$ & $\begin{array}{l}\text { Los registros } \\
\text { observados en las } \\
\text { planificaciones de } \\
\text { aula, apuntan al } \\
\text { desarrollo de } \\
\text { conocimiento } \\
\text { científico escolar en } \\
\text { varias de las } \\
\text { actividades sugeridas. } \\
\text { Se menciona varias } \\
\text { habilidades científicas } \\
\text { dentro del proceso } \\
\text { investigativo como } \\
\text { procedimientos } \\
\text { experimentales, } \\
\text { organización y análisis } \\
\text { de la información, } \\
\text { discusión y exposición } \\
\text { de los resultados. En }\end{array}$ \\
\hline
\end{tabular}




\begin{tabular}{ll}
\hline Profesor & \multicolumn{1}{c}{ Entrevista } \\
\hline AL & $\begin{array}{l}\text { desarrollando de } \\
\text { acuerdo a las } \\
\text { capacidades } \\
\text { individuales. Manifiesta } \\
\text { que la indagación } \\
\text { favorece el desarrollo de } \\
\text { actitudes en los } \\
\text { alumnos, tiene una } \\
\text { finalidad formativa y } \\
\text { ética en el alumno. Se } \\
\text { espera que el alumno } \\
\text { reflexione en cuanto a } \\
\text { sus valores y desarrolle } \\
\text { una concepción propia } \\
\text { del mundo y entorno } \\
\text { que los rodea, que } \\
\text { genere una actitud } \\
\text { positiva hacia la vida y } \\
\text { realizar un aporte } \\
\text { significativo a la } \\
\text { sociedad. }\end{array}$ \\
\end{tabular}

KA

Durante el discurso el docente expresa que la indagación favorece la adquisición de conocimiento científico escolar. Por lo cual, se interpreta que los procesos indagatorios realizados en el aula de ciencias permitirán la obtención de un nuevo conocimiento, entendido como un saber conseguido a partir del estudio, la observación y el análisis de fenómenos naturales o hechos. Desde el discurso el profesor sostiene que el enfoque indagatorio permite promover habilidades de trabajo científico, propias del quehacer en ciencias o habilidades del pensamiento científico.

\section{Observación}

información

relevante utilizando

diversas fuentes, se

observa además

procedimiento

experimental con la

manipulación de

material e

instrumentos de

laboratorio, donde

los alumnos realizan

predicciones,

inferencias y

discuten sus

resultados obtenidos.

Planificación de aula

relación al registro que se evidencia en la

planificación, el

docente estipula abiertamente un trabajo actitudinal con

los estudiantes como fomentar la tolerancia, la transparencia, la probidad. Se pretende que los estudiantes se transformen en ciudadanos, críticos, responsables, respetuosos y creativos.

Durante su actuar en el aula, el docente expresa que una de las finalidades de la indagación es conducir el proceso de adquisición del conocimiento científico, relacionando los conocimientos previos de los alumnos y construyendo un nuevo saber. En relación a lo observado en su actuar durante las clases el profesor evidencia el desarrollo de habilidades científicas.
De acuerdo a estos registros es factible darse cuenta que el profesor presenta una tendencia a desarrollar conocimiento científico disciplinar en sus clases. Basándose en la activación de los conocimientos previos para llegar a la elaboración de un constructo teórico, a través de una serie de estrategias como el empleo de textos, gráficos, esquemas, organizadores, fuentes de información. 


\begin{tabular}{|c|c|c|c|}
\hline Profesor & Entrevista & Observación & $\begin{array}{c}\text { Planificación } \\
\text { de aula }\end{array}$ \\
\hline KA & $\begin{array}{l}\text { De acuerdo con lo } \\
\text { manifiesta el profesor, } \\
\text { lo más relevante } \\
\text { entonces es promover } \\
\text { este tipo de habilidades } \\
\text { de manera transversal } \\
\text { durante todo el ciclo de } \\
\text { aprendizaje del } \\
\text { alumnos, más que } \\
\text { fomentar la adquisición } \\
\text { sólo de contenidos } \\
\text { disciplinarios. La } \\
\text { Indagación Científica se } \\
\text { sustenta también en } \\
\text { promover una actitud } \\
\text { científica en los } \\
\text { estudiantes, la cual } \\
\text { podrá ser también } \\
\text { aplicada a su vida } \\
\text { cotidiana y su contexto } \\
\text { particular, es decir, les } \\
\text { servirán para enfrentar } \\
\text { situaciones } \\
\text { problemáticas de su } \\
\text { diario vivir. }\end{array}$ & $\begin{array}{l}\text { El profesor asume } \\
\text { que dentro del } \\
\text { trabajo experimental } \\
\text { los alumnos hacen } \\
\text { ciencia, se plantean } \\
\text { preguntas, formulan } \\
\text { hipótesis y las ponen } \\
\text { a prueba en un } \\
\text { procedimiento } \\
\text { experimental, } \\
\text { obteniendo } \\
\text { resultados basados } \\
\text { en evidencias. Por lo } \\
\text { consiguiente, este } \\
\text { conjunto de } \\
\text { elementos sería } \\
\text { parte de los procesos } \\
\text { indagatorios que el } \\
\text { profesor implementa } \\
\text { en el aula. Se } \\
\text { evidencia también el } \\
\text { desarrollo de ciertas } \\
\text { actitudes propias del } \\
\text { quehacer científico, } \\
\text { las cuales se } \\
\text { relacionan con la } \\
\text { tolerancia y } \\
\text { perseverancia en el } \\
\text { trabajo científico. }\end{array}$ & $\begin{array}{l}\text { Además para el } \\
\text { profesor sus clases } \\
\text { basadas en indagación } \\
\text { promueven el } \\
\text { desarrollo de } \\
\text { habilidades propias del } \\
\text { quehacer científico, } \\
\text { como habilidades de } \\
\text { investigación, que se } \\
\text { podrían implementar a } \\
\text { través de la } \\
\text { investigación } \\
\text { experimental en el } \\
\text { laboratorio. Se } \\
\text { promueve el desarrollo } \\
\text { de actitudes científicas } \\
\text { como el aprendizaje } \\
\text { colaborativo, tutoría } \\
\text { entre compañeros y } \\
\text { reforzar la } \\
\text { colaboración y la } \\
\text { comunicación. }\end{array}$ \\
\hline
\end{tabular}

En la categoría "Habilidad científica (ver Tabla 5), los docentes se refieren a las habilidades como destrezas cognitivas y motrices que le permita al alumno resolver determinadas situaciones problemáticas. Estas habilidades permiten que los estudiantes sean capaces de realizar planteamientos concretos y ejecutar acciones pertinentes a la investigación. 
Tabla 5. Categoría. Habilidad científica.

\begin{tabular}{|c|c|c|c|}
\hline Profesor & Entrevista & Observación & $\begin{array}{c}\text { Planificación } \\
\text { de aula }\end{array}$ \\
\hline VA & $\begin{array}{l}\text { En su discurso el } \\
\text { docente define a las } \\
\text { habilidades científicas } \\
\text { como capacidades } \\
\text { que el alumno } \\
\text { adquiere a lo largo } \\
\text { del proceso } \\
\text { educativo, estas } \\
\text { habilidades permiten } \\
\text { al estudiante } \\
\text { desarrollar } \\
\text { investigaciones. Se } \\
\text { manifiestan ejemplos } \\
\text { de habilidades } \\
\text { científicas que el } \\
\text { docente estima } \\
\text { conveniente } \\
\text { desarrollar en los } \\
\text { alumnos para que } \\
\text { ellos puedan ir } \\
\text { realizando la } \\
\text { investigación, } \\
\text { menciona como } \\
\text { ejemplos: } \\
\text { Argumentar, } \\
\text { identificar variables, } \\
\text { formular hipótesis, } \\
\text { comunicar resultados. }\end{array}$ & $\begin{array}{l}\text { A través de su } \\
\text { actuar en el aula, el } \\
\text { docente evidencia } \\
\text { considerarlas como } \\
\text { capacidades para } \\
\text { permitir al } \\
\text { estudiante llevar a } \\
\text { cabo una } \\
\text { investigación. Inicia } \\
\text { con la propuesta de } \\
\text { un contenido para } \\
\text { que los alumnos } \\
\text { puedan generar a } \\
\text { partir de él una } \\
\text { problemática } \\
\text { indagatoria. } \\
\text { Posterior a eso, los } \\
\text { alumnos tratan de } \\
\text { plantearse } \\
\text { preguntas } \\
\text { investigables, } \\
\text { realizando } \\
\text { predicciones, } \\
\text { discutiendo sus } \\
\text { resultados y } \\
\text { argumentar. }\end{array}$ & $\begin{array}{l}\text { En las actividades } \\
\text { propuestas en la } \\
\text { planificación se } \\
\text { evidencia que el } \\
\text { profesor utiliza ciertas } \\
\text { habilidades científicas } \\
\text { dentro del proceso } \\
\text { investigativo, se } \\
\text { entrega instrucciones } \\
\text { para la búsqueda de } \\
\text { información } \\
\text { bibliográfica, } \\
\text { procedimientos } \\
\text { experimentales, } \\
\text { análisis de la } \\
\text { información, discusión } \\
\text { y exposición de los } \\
\text { resultados. }\end{array}$ \\
\hline $\mathbf{A L}$ & $\begin{array}{l}\text { Desde su discurso el } \\
\text { docente se refiere a } \\
\text { las habilidades como } \\
\text { destrezas cognitivas y } \\
\text { motrices que le } \\
\text { permita al alumno } \\
\text { resolver } \\
\text { determinadas } \\
\text { situaciones } \\
\text { problemáticas, que } \\
\text { sean capaces de } \\
\text { realizar } \\
\text { planteamientos } \\
\text { concretos y ejecutar } \\
\text { acciones pertinentes, } \\
\text { generar deducciones } \\
\text { a partir de un hecho } \\
\text { concreto del diario } \\
\text { vivir, esto es propicio } \\
\text { para que el alumno } \\
\text { idóneamente elabore } \\
\text { un modelo mental } \\
\text { para alcanzar una } \\
\text { cognición que le } \\
\text { permita transferir ese } \\
\text { conocimiento a otra } \\
\text { situación } \\
\text { problemática. }\end{array}$ & $\begin{array}{l}\text { En las clases } \\
\text { observadas y } \\
\text { principalmente en } \\
\text { laboratorio el } \\
\text { docente persigue } \\
\text { promover una serie } \\
\text { de habilidades } \\
\text { científicas } \\
\text { consideradas como } \\
\text { destrezas motrices } \\
\text { (manipulación de } \\
\text { material de } \\
\text { laboratorio) y } \\
\text { destrezas cognitivas } \\
\text { (formulación de } \\
\text { hipótesis, realizar } \\
\text { predicciones, } \\
\text { inferencias, } \\
\text { observaciones, } \\
\text { predicciones) para } \\
\text { conducir la } \\
\text { investigación } \\
\text { científica propuesta } \\
\text { en la clase. }\end{array}$ & $\begin{array}{l}\text { En el registro de las } \\
\text { planificaciones de aula } \\
\text { se observan diversas } \\
\text { actividades } \\
\text { relacionadas con } \\
\text { habilidades científicas } \\
\text { que, de acuerdo a la } \\
\text { concepción en el } \\
\text { discurso se asumen } \\
\text { como destrezas } \\
\text { motrices y cognitivas, } \\
\text { pero las actividades } \\
\text { sugeridas apuntan } \\
\text { específicamente a } \\
\text { habilidades de } \\
\text { pensamiento científico } \\
\text { que involucran un } \\
\text { proceso cognitivo } \\
\text { superior como evaluar, } \\
\text { debatir y analizar. }\end{array}$ \\
\hline
\end{tabular}




\begin{tabular}{|c|c|c|c|}
\hline Profesor & Entrevista & Observación & $\begin{array}{c}\text { Planificación } \\
\text { de aula }\end{array}$ \\
\hline $\mathbf{K A}$ & $\begin{array}{l}\text { Se manifiesta que las } \\
\text { habilidades de } \\
\text { investigación son } \\
\text { consideradas como } \\
\text { destrezas que el } \\
\text { alumno debe } \\
\text { desarrollar para } \\
\text { hacer ciencia escolar, } \\
\text { se interpreta } \\
\text { entonces, que para el } \\
\text { profesor tales } \\
\text { capacidades } \\
\text { conducirían al } \\
\text { estudiante a realizar } \\
\text { actividades propias } \\
\text { del mundo científico. } \\
\text { Se hace mención } \\
\text { además de las } \\
\text { habilidades de } \\
\text { pensamiento } \\
\text { científico, } \\
\text { entendiéndose como } \\
\text { una habilidad de nivel } \\
\text { o desarrollo más bien } \\
\text { cognitiva que } \\
\text { procedimental. Hace } \\
\text { mención de análisis } \\
\text { de gráficos, } \\
\text { resolución de } \\
\text { problemas, } \\
\text { investigación } \\
\text { bibliográfica, } \\
\text { formular hipótesis, } \\
\text { comparar variables } \\
\text { de estudio, diseñar un } \\
\text { procedimiento } \\
\text { experimental y } \\
\text { elaborar } \\
\text { conclusiones. }\end{array}$ & $\begin{array}{l}\text { Desde su actuar } \\
\text { docente, la } \\
\text { concepción que } \\
\text { presenta de } \\
\text { habilidad científica } \\
\text { condice con su } \\
\text { práctica en el aula, } \\
\text { al desarrollar la } \\
\text { curiosidad, hacerse } \\
\text { preguntas que } \\
\text { conduzcan a } \\
\text { investigación y } \\
\text { buscar información } \\
\text { relevante para } \\
\text { apoyar el proceso } \\
\text { investigativo, esto } \\
\text { está principalmente } \\
\text { enfocado en el } \\
\text { trabajo } \\
\text { experimental en el } \\
\text { laboratorio. Se } \\
\text { puede visualizar el } \\
\text { análisis de los } \\
\text { resultados } \\
\text { obtenidos en el } \\
\text { procedimiento } \\
\text { experimental, se } \\
\text { realizan preguntas, } \\
\text { interpretaciones, se } \\
\text { evalúan las } \\
\text { predicciones } \\
\text { iniciales y se } \\
\text { organiza la } \\
\text { información para } \\
\text { confeccionar un } \\
\text { informe escrito. }\end{array}$ & $\begin{array}{l}\text { A través de este } \\
\text { registro es posible } \\
\text { interpretar que para el } \\
\text { profesor la ejecución de } \\
\text { una investigación } \\
\text { experimental en } \\
\text { laboratorio promueve el } \\
\text { desarrollo de } \\
\text { habilidades de } \\
\text { investigación científica, } \\
\text { de acuerdo a la } \\
\text { concepción que el } \\
\text { profesor presenta como } \\
\text { destrezas que el } \\
\text { alumno debe } \\
\text { desarrollar para hacer } \\
\text { ciencia escolar. Estás } \\
\text { habilidades están } \\
\text { relacionadas con } \\
\text { planteamientos de } \\
\text { preguntas, formulación } \\
\text { de hipótesis, } \\
\text { procedimiento } \\
\text { experimental, } \\
\text { elaboración de } \\
\text { conclusiones, entre } \\
\text { otras. }\end{array}$ \\
\hline
\end{tabular}

De acuerdo con lo sintetizado, fue posible elaborar un modelo para visualizar, de forma gráfica, lo que para cada profesor es la Indagación Científica. En la Figura 1 se muestra la indagación científica según el profesor VA. 


\section{LA INDAGACION SEGÚN PROFESOR VA}

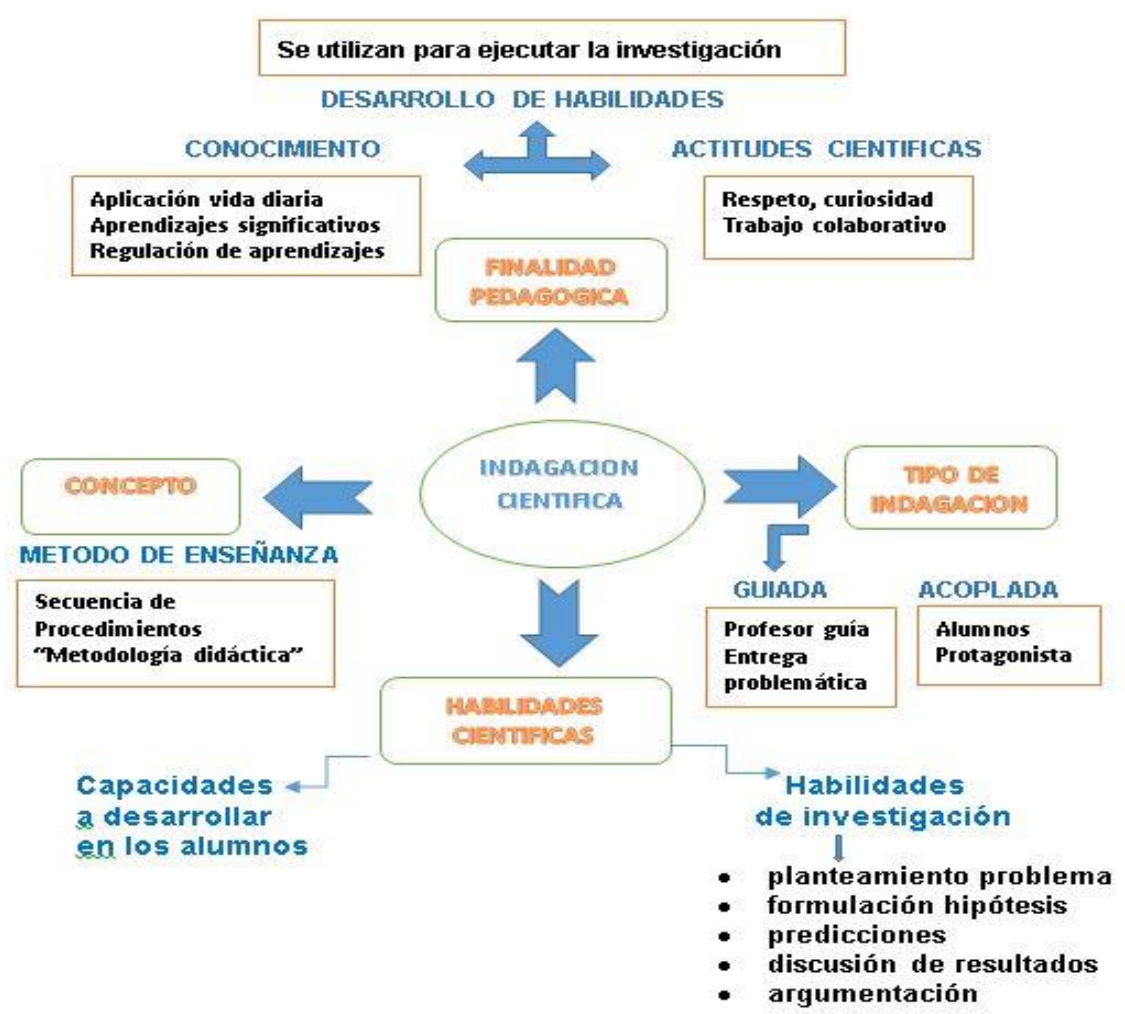

Figura 1. Indagación científica según el profesor V.

Del análisis de este esquema, se visualiza a un profesor que presenta una base epistémica de indagación, desde su concepción conoce su finalidad pedagógica, pero no así, el sustento desde el campo de la didáctica como enfoque de enseñanza. Este profesor presenta un cuerpo de conocimientos, claramente asimilados por el programa de perfeccionamiento en indagación científica que fue partícipe, así lo menciona en parte de la entrevista realizada, que le permite desenvolverse discretamente en su actuar docente. Tiene claridad y está convencido que esta nueva propuesta de enseñanza es diferente en varios aspectos a la enseñanza tradicional en ciencias. Deja de manifiesto que la indagación científica promueve el desarrollo de conocimiento, actitudes y habilidades propias del quehacer científico, de esta manera, su discurso, su actuar docente y su planificación de aula contratan con su conocimiento sobre este modelo de enseñanza.

Por lo anteriormente expuesto se reafirma que el discurso del profesor incluye una base consolidada de elementos propios de la indagación científica, el docente conoce sobre indagación, 
manifiesta un conocimiento que probablemente ha desarrollado gracias a su reciente participación en un programa de formación continua relacionado con la Indagación Científica y así lo manifiesta en los procesos indagatorios que desarrolla en el aula y en las planificaciones de sus clases. Existe entonces, una concordancia entre lo que el docente piensa, dice y hace con respecto a la indagación científica. Si bien es cierto, desde su concepción la nombra como metodología indagatoria, presenta claridad en la finalidad pedagógica de aplicar indagación en el aula: para promover habilidades de investigación, actitudes y conocimiento científico en sus estudiantes.

En el discurso del docente se aprecia un lenguaje simple, sencillo, quizás no demasiado consolidado de terminología conceptual teórica, pero pone de manifiesto su interés por la pedagogía, por trabajar con niños, por mostrarles esta nueva perspectiva de enseñanza, marcando un antes y después de su participación en programas de indagación en su desarrollo profesional docente. Sus clases también condicen y tributan al modelo indagatorio, el docente conoce y aplica las etapas del proceso indagatorio y sus alumnos asimilan esto como un contenido disciplinar más dentro del aula.

En la Figura 2 se observa la indagación científica según el profesor AL, del análisis de este esquema, se visualiza a un profesor que presenta una base epistemológica que le permite tener un cavado conocimiento de indagación científica. De acuerdo a su concepción, el docente ubica a la indagación como un enfoque didáctico, un modelo de enseñanza de las ciencias, que puede ser aplicado en las aulas para lograr ciertos saberes propios del quehacer científico, lo considera como una forma de hacer ciencia escolar símil a la ciencia que realizan los eruditos. Entrega fundamentos sólidos sobre la finalidad pedagógica de aplicar este modelo de enseñanza en las aulas de ciencias, dejando establecido que la indagación científica promueve el desarrollo de conocimientos, actitudes y habilidades que caracterizan al trabajo científico.

De esta manera, su discurso, su actuar docente y su planificación de aula condicen con su conocimiento sobre este modelo de enseñanza. En relación con el tipo de indagación que el docente desarrolla en el aula, está dirigida a orientar y guiar al 
estudiante en su proceso de aprendizaje, es el docente quien articula un proyecto de investigación científica para ser desarrollado por los alumnos, es decir, dejar que el estudiante busque, investigue y reflexione desde su propia perspectiva; motivarlo e incentivarlo para hacer un trabajo científico en conjunto. Por lo consiguiente, sus clases basadas en indagación están orientadas a generar habilidades científicas, entendidas como un conjunto de destrezas cognitivas y motrices que permitan al estudiante resolver diversas situaciones problemáticas. Estas habilidades señaladas como habilidades de investigación y de pensamiento científico, las cuales involucran procesos cognitivos superiores como inferencia, análisis, evaluación, discusión, argumentación y construcción de modelos mentales.

\section{LA INDAGACION PARA EL PROFESOR AL}

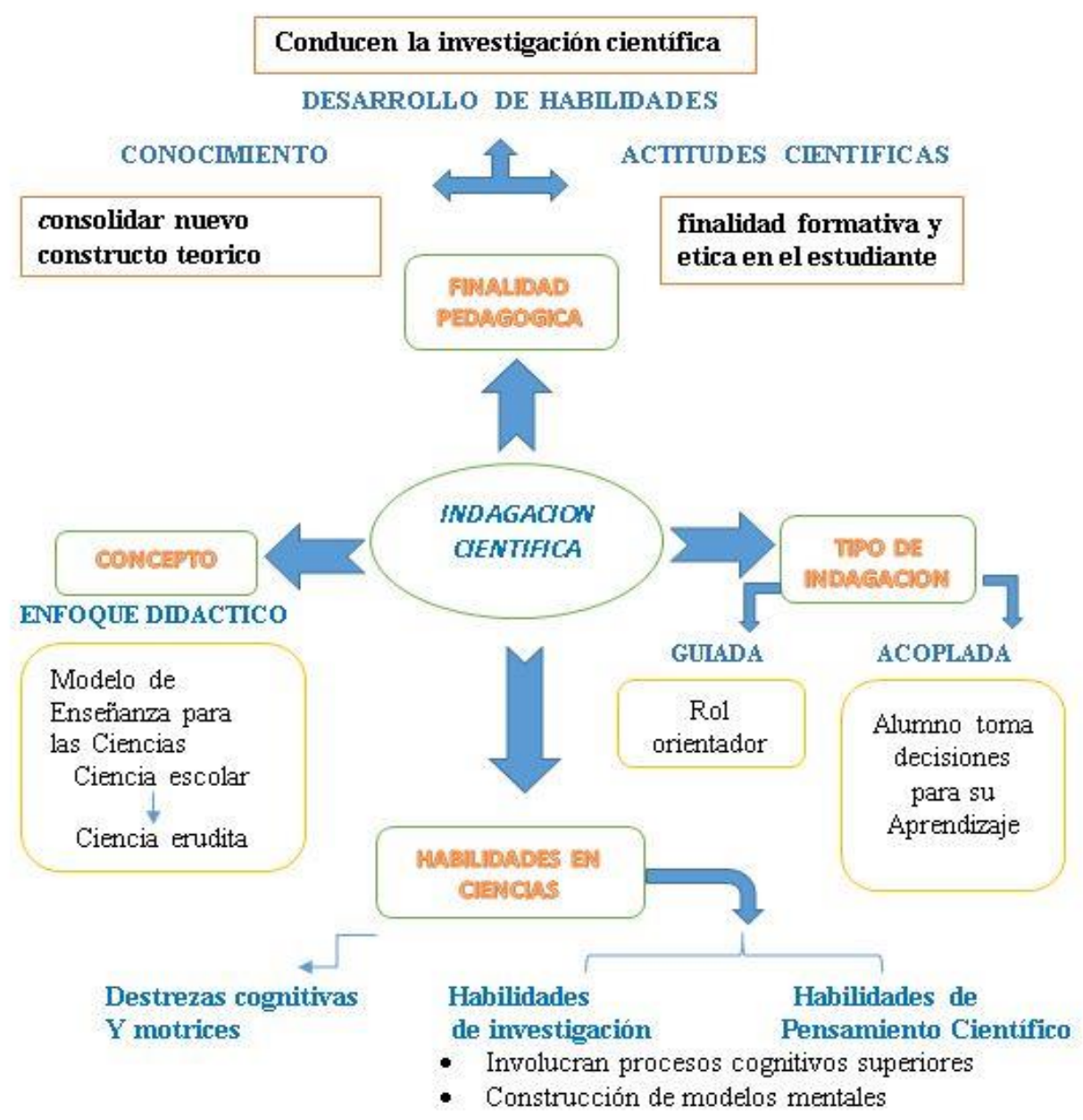

Figura 2. La indagación científica según el profesor AL. 
En relación con el desarrollo de actitudes científicas que promueve este enfoque, el docente considera que la indagación, tiene una finalidad formativa y ética en el alumno, se espera que este reflexione en cuanto a sus valores y desarrolle una concepción propia del mundo y del entorno que lo rodea, que genere una actitud positiva hacia diversas problemáticas, cumpliendo con un aporte significativo a la sociedad. Resumiendo lo anterior se puede afirmar que el docente presenta una consolidada base de conocimientos sobre indagación científica que guían sus actos de enseñanza en aula y consolidan su ejercicio docente.

En la Figura 3 se muestra la indagación científica según el profesor KA, del análisis de este esquema, es factible visualizar un profesor que presenta una base cognitiva sobre indagación, desde su concepción conoce su finalidad pedagógica, pero no así, el sustento desde el campo de la didáctica como enfoque de enseñanza. Su cuerpo de conocimientos le permite desenvolverse moderadamente en su actuar docente. Deja de manifiesto que la indagación científica es una metodología que utiliza diferentes estrategias de enseñanza relacionadas con la actividad científica escolar, aludiendo a una secuencia de procedimientos que deben realizarse para adquirir conocimiento científico. 


\section{LA INDAGACIÓN PARA EL PROFESOR KA}

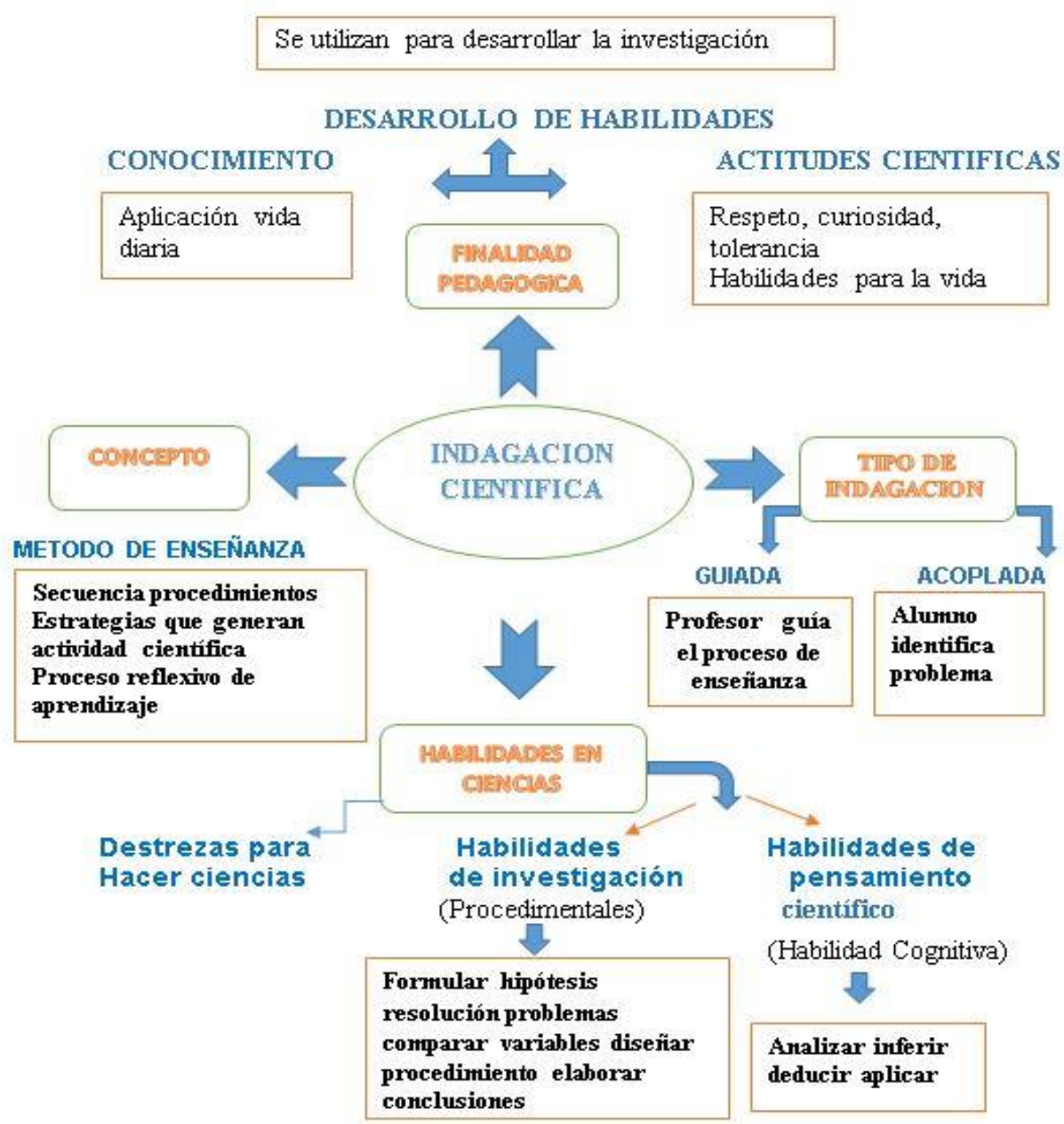

Figura 3. Indagación científica según el profesor KA.

El docente en estudio claramente se identifica como un profesor que guía y orienta el trabajo en aula, ya que es él quien dirige a los estudiantes para realizar las actividades propuestas en el marco de la indagación, sin embargo, se entrega libertad al estudiante, en ciertas ocasiones, para tomar decisiones en las acciones a seguir que conducirán a buscar soluciones y alcanzar el aprendizaje. De acuerdo con la finalidad pedagógica de implementar la indagación científica en el aula, el docente sostiene, que este modelo promueve el desarrollo de conocimiento, actitudes y habilidades propias del quehacer científico. El desarrollo del conocimiento científico escolar debe ser aplicado a situaciones de la vida diaria y el desarrollo de las actitudes propias del trabajo en ciencias como el respeto por las 
ideas de los demás, la tolerancia, persistencia, flexibilidad y trabajo en equipo, serán aplicadas a su entorno particular y les servirán para enfrentar situaciones problemáticas de su diario vivir.

Con los casos analizados, es posible interpretar los procesos de indagación científica que promueven en el aula de ciencias los profesores en estudio cuando desarrollan las clases bajo este enfoque didáctico. El análisis general de los tres casos en estudio permite afirmar que cada uno de los docentes presenta una concepción de indagación científica con ciertos matices que coinciden con lo que la literatura dice respecto a este modelo de enseñanza. Para los profesores, la indagación puede ser concebida como una metodología de enseñanza o como un enfoque didáctico. La génesis de esta diferencia puede estar relacionada con los procesos de formación y desarrollo del ejercicio profesional docente, lo que acarrea un soporte teórico y epistemológico en los fundamentos de este modelo y en especial dentro del campo de la didáctica de las ciencias. Sin embargo, cuando se habla de la finalidad pedagógica de implementar la indagación científica, todos los profesores en estudio coinciden que este enfoque de enseñanza permite el desarrollo de conocimiento científico, actitudes y habilidades de investigación.

A continuación en la Figura 4 se visualiza en un esquema el resumen de lo que es la indagación científica para los tres profesores en estudio. 


\section{LA INDAGACION CIENTIFICA PARA LOS PROFESORES}

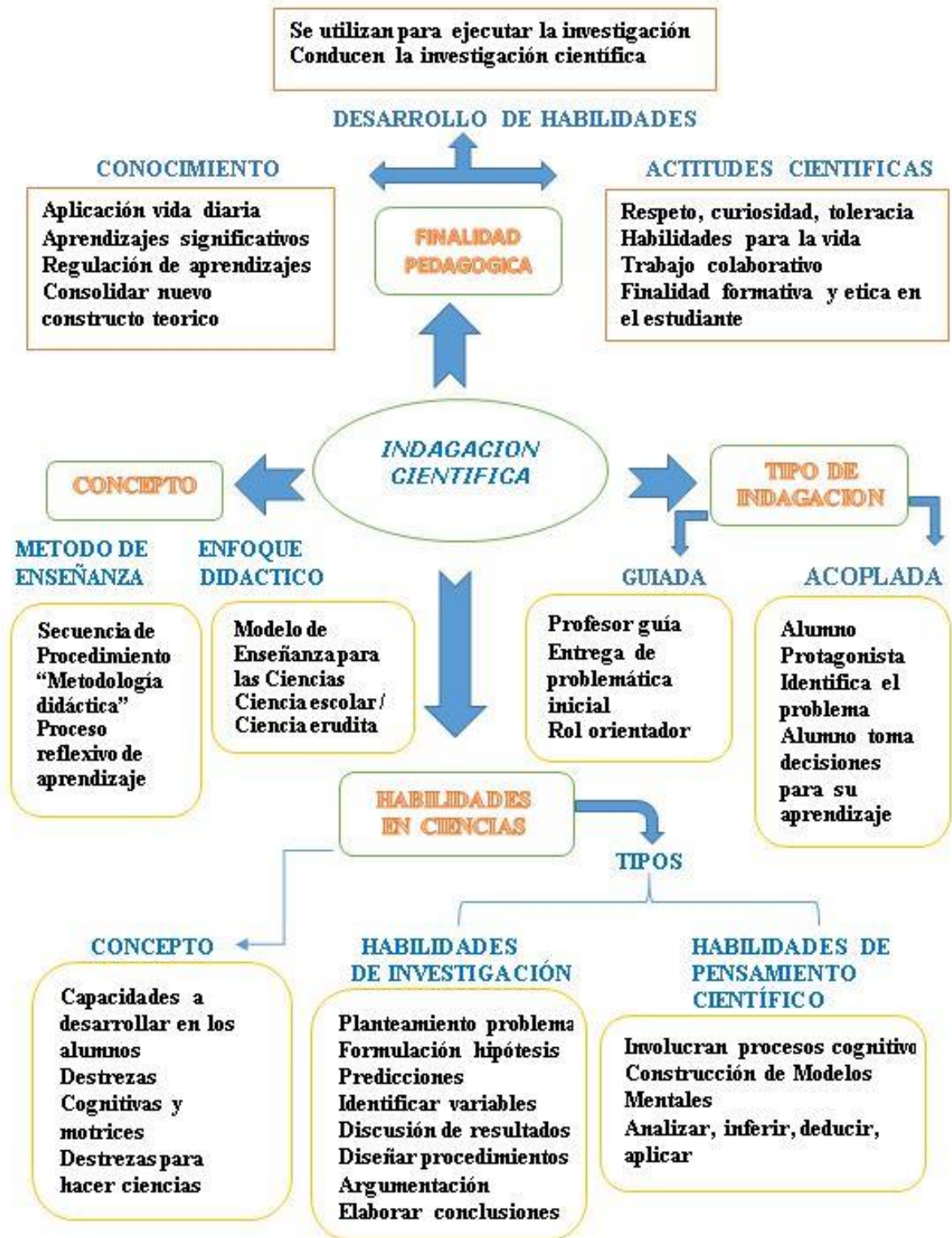

Figura 4. La indagación científica para los profesores en estudio.

\section{CONCLUSIONES}

partir de los hallazgos develados se puede concluir que los profesores en estudio presentan distintas concepciones de 1 indagación científica, para algunos la indagación es pensada como una metodología de enseñanza, que incorpora distintas actividades 0 estrategias para generar actividad científica en los alumnos. Es también entendida como una 
metodología que es capaz de sacar al alumno de lo rutinario, abandonando la enseñanza tradicional en ciencias y permitiendo a los estudiantes obtener aprendizajes significativos.

Cuando se habla de la indagación como un enfoque didáctico o modelo de aprendizaje se alude a propósitos pedagógicos más ambiciosos, ya que constituye un proceso complejo que promueve el desarrollo progresivo de conocimientos y comprensión de ideas científicas fundamentales a partir de actividades similares a las que realizan los científicos o eruditos en la producción científica.

Los docentes participantes se consideran profesores indagadores, es decir, ellos aplican procesos indagatorios en el aula de ciencias, aunque estos procesos resultaron ser escasos y evidenciables sólo en algunas de sus clases. Se observa en los profesores una marcada tendencia a realizar una indagación guiada, donde el profesor asume el rol de guía, orientando y dirigiendo al estudiante en la búsqueda de la respuesta a una situación problemática inicial.

También es posible encontrar una indagación de tipo acoplada según la clasificación hecha por Martin-Hansen (2002), donde se entrega cierta libertad al alumno para la toma de decisiones en los procedimientos y pasos a seguir en la investigación en búsqueda de soluciones a la problemática inicial.

De acuerdo a los resultados obtenidos es posible concluir que para todos los profesores implicados en este estudio, el propósito de implementar indagación en sus aulas apunta a promover en los estudiantes el desarrollo de habilidades, conocimientos y actitudes propias del quehacer científico. En relación con el proceso de adquirir conocimiento científico, se pone de manifiesto la importancia que tiene para los profesores generar conocimiento significativo en el aula y que el alumno logre la aplicación de estos conocimientos y saberes adquiridos a situaciones de la vida cotidiana.

Resulta trascendental la idea de promover habilidades de trabajo científico y de pensamiento científico, sacar a los alumnos del aula tradicional para que investiguen y descubran por sí mismos fenómenos naturales de acuerdo a su entorno, a su contexto particular, basándose en evidencias concretas. Los profesores además señalan que las actividades que involucren 
investigación y que promuevan estas habilidades, deben considerar las capacidades individuales de cada estudiante.

En relación con el tipo de habilidades promovidas en los estudiantes y de acuerdo a los resultados obtenidos es posible concluir que los docentes presentan una batería de habilidades expresadas tanto en sus discursos, en sus prácticas docentes y en las planificaciones de aula que rigen su actuar en el aula. Es posible entonces mencionar a habilidades de investigación que son consideradas de carácter más bien procedimental y habilidades de pensamiento científico relacionadas con un proceso cognitivo más elaborado. Entre las habilidades promovidas por los docentes en estudio se puede señalar: planteamiento de una pregunta de investigación, formulación de hipótesis e identificación de variables, diseño de procedimientos experimentales, búsqueda de información bibliográfica, organización y análisis de la información, discusión y exposición de los resultados, realizan predicciones, inferencias y análisis.

El desarrollo de habilidades y conocimiento científico está acompañado además de ciertas actitudes propias de trabajo en ciencias pero también pueden aplicarse a la vida personal del estudiante, persiguen desarrollar la curiosidad del entorno, la búsqueda de la verdad, el trabajo colaborativo, el respeto hacia el trabajo de los demás.

En este sentido, la indagación científica favorece el desarrollo de actitudes en los alumnos, permitiendo una finalidad formativa y ética en el estudiante. Se espera que el alumno reflexione en cuanto a sus valores y desarrolle una concepción propia del mundo y entorno que le rodea, que genere una actitud positiva hacia la vida realizando un aporte significativo a la sociedad. Los profesores manifiestan abiertamente un trabajo actitudinal con los estudiantes para fomentar la tolerancia, la transparencia, la probidad, pretendiendo con ello que los estudiantes se transformen en ciudadanos, críticos, responsables y respetuosos.

Por último, las conclusiones y reflexiones realizadas sobre la indagación científica permiten abrir la discusión sobre los desafíos de implementar nuevos enfoques de enseñanza en ciencias, que promuevan diversas formas de enseñar y aprender las ciencias naturales en las escuelas, en el contexto de una sociedad del conocimiento, heterogénea y cambiante. Por esta razón, es 
necesario conocer como en las escuelas estos nuevos enfoques o modelos son aplicados a su contexto escolar de acuerdo a las concepciones de enseñanza presentes en los profesores de ciencias que los desarrollan.

\section{REFERENCIAS}

Abell, S., D. Smith y Volkmann, M. (2006). Inquiry in Science Teacher Education. En Flick, L y N. Lederman (Eds.), Scientific inquiry and the nature of science: Implications for teaching, learning, and teacher education, pp. 389-425. Springer: Netherlands

Anderson, R. D. (2007). Inquiry as an organizing theme for science curricula. En: Abell, S. K., Lederman, N. G. (eds.), Hand book of Research on Science Education, pp. 808-830. New York: Routledge

Arteaga Valdés, E., Armada Arteaga, L., y Del Sol Martínez, J. L. (2016). La enseñanza de las ciencias en el nuevo milenio. Retos y sugerencias. Revista Universidad y Sociedad, 8(1). 169-176

Barrow, L. H., (2006) A Brief History of Inquiry: From Dewey to Standards, Journal of Science Teacher Education, 17, 265- 278, 2006

Bevins, S. y Price, G. (2016) Reconceptualising inquiry in science education. International Journal of Science Education, 38(1), 1729

European Union (2015). Science Education for Responsible Citizenship. Luxembourg: Publications Office of the European Union. Recuperado

de http://ec.europa.eu/research/swafs/pdf/pub education/KI-NA-26-893-EN-N.pdf

Dewey, J. (1910). Science as subject-matter and as method, Science, $31,121-127$

García R., J. A. (2011). Modelo educativo basado en competencias: importancia y necesidad. Revista Electrónica "Actualidades Investigativas en Educación", 11(3), 1-24. Recuperado de https://www.redalyc.org/pdf/447/44722178014.pdf

Gibbs, G. (2012). El análisis de datos cualitativos en investigación cualitativa. Madrid: Morata

González-Weil, C., Cortés, M., Bravo, P., Ibaceta, I., Cuevas, K., Quiñones, P., Maturana, J. y Abarca, A. (2012). La indagación científica como enfoque pedagógico: estudio sobre las prácticas innovadoras de docentes de ciencia en EM (Región de Valparaíso). Estudios Pedagógicos, 38(2), 85-102 
Lederman N.G., Lederman J.S., Antink A. (2013) Nature of science and scientific inquiry as contexts for learning of science and achievement of scientific literacy. International Journal of Education in Mathematics, Science and Technology ,1(3), 138 147

Martin-Hansen, L. (2002). Defining Inquiry. The Science Teacher, 69(2), 34-37

Ministerio de Educación [MINEDUC] (2009). Objetivos Fundamentales y Contenidos Mínimos Obligatorios de la Educación Básica y Media Actualización 2009. Gobierno de Chile

National Research Council, [NRC] (1996). National Science Educational Standars. Washington. National Academy Press

Pedaste M., Mäeots M., Siiman L.A., De Jong T., Van Riesen S.A., Kamp E.T., Tsourlidaki E. (2015). Phases of inquiry-based learning: Definitions and the inquiry cycle. Educational research review, 14, 47-61

Simons, H. (2011). El estudio de caso: teoría y práctica. Madrid: Morata 